\title{
Weaving length and lane-changing behavior at two-sided weaving section along federal road FT050: jalan kluang - ayer hitam
}

\author{
Joewono Prasetijo ${ }^{1, *}$, Ishak Baba ${ }^{1}$, Nurul Elena A. Arifin ${ }^{1}$, and Alvin John L. M. Siang ${ }^{1}$ \\ ${ }^{1}$ Universiti Tun Hussein Onn Malaysia, Faculty of Engineering Technology, Department of \\ Transportation Engineering Technology, Johor, Malaysia \\ ${ }^{2}$ Universiti Tun Hussein Onn Malaysia, Faculty of Civil and Environmental Engineering, Johor, \\ Malaysia
}

\begin{abstract}
Weaving is defined as a movement of vehicles that crossing over the direct traffic from on-ramp to off-ramp. Apparently, weaving maneuver lead to collision risk and weaving turbulence especially at twosided weaving section. The following study recognize the maximum weaving length and lane-changing rate on Federal Route 50 (FT050) segment. Visual recording technique was used at two different locations that are called as Site A (KM15) and Site B (KM16). Data of traffic volume was extracted by playback the video/personal computer. Analysis was made using spreadsheet and applied the methodology of the Highway Capacity Manual 2010. The study found that Site A has more tendencies to encounter longer weaving turbulence with maximum weaving length ranging from $1952 \mathrm{~m}$ to $2120 \mathrm{~m}$, compared to site $\mathrm{B}$ that is $1866 \mathrm{~m}$ to 1882 $\mathrm{m}$. Site A with a longer distance of weaving section $358 \mathrm{~m}$ has higher intense of total lane-changing rate that is $1142 \mathrm{lc} / \mathrm{h}$ compared to Site B with a distance of weaving section $316 \mathrm{~m}$ has total lane-changing rate of $812 \mathrm{lc} / \mathrm{h}$. Shorter weaving distance may cause less lane-changing activity because drivers does not prefer to perform weaving at shorter weaving section as it is forced the drivers to perform weaving drastically in more crammed situation and risk to dealing with accident is huge. The findings shall help to understand more on causes of weaving turbulence at weaving section by referring HCM 2010 methodology.
\end{abstract}

\section{Introduction}

Weaving is an action that performed by merging traffic to cross the through lane over diverging movements [1]. Basically, weaving is considered as types of conflict that occurred in daily traffic and traffic streams conflicts are very common at any of weaving sections and intersections [2]. A weaving maneuver performed by drivers is normally depending on their own purpose. However, inefficiencies of driver when perform weaving

\footnotetext{
* Corresponding author: joewono@uthm.edu.my
} 
will finally lead to risk of accident and also confusing maneuver [3, 4]. A weaving maneuver could be detected by the driver on direct traffic when the weaving's driver gives signal to change lane. Effect of the lane-changing of the weaving vehicles along a weaving segment could create weaving turbulence. As weaving creates conflict streams, therefore, the traffic streams behavior should be considered based on the current fundamental traffic theory [5].

Since collision risk at weaving section is large, human error could be one of the biggest factors. Somehow, by prevention this error, there might be a high probability to reduce the accident risk $[6,7]$. In traffic engineering view, the collision risk at weaving section might be influenced by the length of the weaving segment itself. Previous study [8] proved that longer distance of weaving cause less collision risk because its influence the driver decision to change lane safely. If longer weaving section is more preferred by most of driver to perform weaving, then activity of lane changing is become higher as the volume of vehicles is increase. Affected by this is weaving turbulence that will be created by the increasing volume of vehicles and this could be measured by analyze the maximum weaving length of the section. Therefore, this study is carried out to investigate the maximum weaving length and lane-changing rate which is affected by volume ratio and weaving length at different sites. Methodology of chapter 12 in Highway Capacity Manual (HCM) 2010 is applied to assist the analysis.

\subsection{Review on weaving behavior}

A study on weaving section was conducted as early in 1965 by HCM which is the length of weaving section which used as approach. Since that, a lot of studies were conducted in order to analyze a weaving section in order to investigate the length, flow, lane-changing rate, capacity and speed. Basic purpose of investigating these is due to a problem regarding to weaving turbulence. This problem is often formed within the weaving section [9]. However, there is a lack of method used in HCM 1965 which is the volume and flows of non-weaving was not taken into consideration to analyze the rate of lane-changing. Year by year, HCM was upgraded in order to provide the best methodology of weaving analysis and finally the latest version of HCM was published in 2010. The methodology of freeway weaving analysis in HCM was adapted by the report of NCHRP which is a study was conducted in order to develop a new model or methodology for maximum weaving length and lane-changing rate. New version of HCM used one-sided and two-sided instead of using 'Type' to classify the weaving's configuration. Two-sided weaving section is classic and special as it is frequently occur on multilane highways and ramp to ramp flow is a main subject of analysis [10].

Due to weaving maneuver, lane-changing activity is become more aggressive in purpose of avoiding weaving vehicles. There were a lot of studies regarding to lane-changing in traffic but somehow lane-changing at weaving section is more complex compared to other situation [6]. Gap acceptance is a very famous approach in order to analyze lane-changing activity. Lane-changing at a roundabout also complex as a lot of confusing and weaving maneuver which was studied mostly by using gap acceptance approach. Speed adjustment is also one of approach used and studied by Uno as a speed adjustment model was developed to analyze speed adjustment processes of a lane-changing vehicle at weaving section. However, both approaches could not be applied as it does not measure a weaving turbulence impact. Approach of HCM 2010 is the best to use in order to analyze lanechanging rate at weaving section so that the impact of weaving turbulence could be known. 


\section{Discussion}

It was earlier explained that data analysis was made using HCM 2010. Early stage of analysis is to find the short length $L_{S}$ which will be as weaving length and also base length $L_{B} . L_{S}$ is measured between the end point of any barrier marking that prohibit lane-changing while $L_{B}$ is measured between right edge and left edge of the ramp meet. If there is no barrier found, $L_{S}=L_{B}$. Otherwise, if there is any presence of barrier, Eq. (1) is used.

$$
L_{s}=0.77 \times L_{B}
$$

To determine at which distance the weaving section no longer has an impact of turbulence, maximum weaving length will be calculated using Eq. (2). It shows that the length of maximum weaving at certain weaving section is sensitive to volume ratio $V R$ and number of weaving lanes $N_{W L}$. As stated in HCM 2010, $N_{W L}$ is defined as zero for two-sided weaving. Therefore, only $V R$ used as function and it use volume adjustment from volume data that calculated as in Eq. (3) through Eq. (7). Finding of $L_{M A X}$ will be compared with value of $L_{S}$ in order to specify if the section studied should be analyzed as weaving section or isolated merging and diverging. HCM 2010 specifies that a studied section only could be analyzed as weaving section if the value

$$
\begin{gathered}
V R=\frac{V_{W}}{V} \\
L_{\text {MAX }}=[5,728(1+V R) 1.6]-[1,566 N W L]
\end{gathered}
$$

where,

$\mathrm{V}_{\mathrm{W}}=$ total weaving flow $(\mathrm{pc} / \mathrm{h})$

$\mathrm{V}=$ total demand flow

$$
\begin{gathered}
V_{p}=\frac{V}{P H F \times f_{H V} \times f_{P}} \\
V_{p}=V_{N W}+V_{W}
\end{gathered}
$$

where,

$\mathrm{PHF}=$ peak hour factor

$\mathrm{f}_{\mathrm{p}}=1.00$ (assume drivers are familiar with the site)

$\mathrm{f}_{\mathrm{HV}}=$ heavy-vehicle factor

$$
P H F=\frac{V}{4 \times V_{15}}
$$

where,

$\mathrm{V}=$ peak hourly volume

$\mathrm{V}_{15}=$ highest 15-minute volume

$$
f_{H V}=\frac{1}{1+P_{T}\left(E_{T}-1\right)}
$$


Where,

$\mathrm{P}_{\mathrm{T}}=$ percentage of trucks and buses

$\mathrm{E}_{\mathrm{T}}=$ passenger car equivalent for trucks and buses as in (Table 1)

Table 1 Passenger Car Equivalents for Extended General Highways

\begin{tabular}{|c|c|c|c|}
\hline \multirow{2}{*}{ Factor } & \multicolumn{3}{|c|}{ Type of Terrain } \\
\cline { 2 - 4 } & Level & Rolling & Mountainous \\
\hline ET (truck and buses) & 1.5 & 2.5 & 4.5 \\
E $_{\mathrm{R}}$ (RVs) & 1.2 & 2.0 & 4.0 \\
\hline
\end{tabular}

Since lane-changing at weaving section consist of weaving and non-weaving maneuver, then analysis of lane-changing rate for both maneuver could be analyzed. This could be done by using Eq. (8) through Eq. (13). Calculation of non-weaving lane-changing rate requires index number in order to specify which formula between Eq. (11) to Eq. (13) should be use. To specify which equation should be use, the index number should fulfill the condition as stated below:

$$
\begin{aligned}
\text { If } \mathrm{I}_{\mathrm{NW}} \leq 1,300: & \mathrm{LC}_{\mathrm{NW}}=\mathrm{LC}_{\mathrm{NW} 1} \\
\text { If } \mathrm{I}_{\mathrm{NW}} \geq 1,950: & \mathrm{LC}_{\mathrm{NW}}=\mathrm{LC}_{\mathrm{NW} 2} \\
\text { If } 1,300<\mathrm{I}_{\mathrm{NW}}<1,300: & \mathrm{LC}_{\mathrm{NW}}=\mathrm{LC}_{\mathrm{NW} 3} \\
\text { If } \mathrm{LC}_{\mathrm{NW} 1} \geq \mathrm{LC}_{\mathrm{NW} 2}: & \mathrm{LC}_{\mathrm{NW}}=\mathrm{LC}_{\mathrm{NW} 2} \\
L C_{W}=L C_{\text {MIN }}+0.39\left[\left(L_{S}-300\right)^{0.5} N^{2}(1+I D)^{0.8}\right] &
\end{aligned}
$$

where,

$\mathrm{LC}_{\mathrm{w}}=$ Equivalent hourly rate at which weaving vehicles make lane changes within the weaving segment $(\mathrm{lc} / \mathrm{h})$

$\mathrm{LC}_{\min }=$ Minimum equivalent hourly rate at which weaving vehicles must make lane changes within the weaving segment to successfully complete all weaving maneuvers $(\mathrm{lc} / \mathrm{h})$

$\mathrm{L}_{\mathrm{s}} \quad=$ Length of the weaving segment using the short length definition ( $\mathrm{ft}$ ) $300 \mathrm{ft}$ is the minimum value

$\mathrm{N}=$ Number of lanes within the weaving segment; and

ID $\quad=$ Interchange Density (int $/ \mathrm{mi})$

$$
\begin{gathered}
L C_{M I N}=L C_{R R} \times V_{R R} \quad \text { (for two sided) } \\
I_{N W}=\frac{L_{S} \times I D \times V_{N W}}{10,000} \\
L C_{N W 1}=\left(0.206 V_{N W}\right)+\left(0.542 L_{S}\right)-(192.6 \mathrm{~N}) \\
L C_{N W 2}=2,135+0.223\left(V_{N W}-2000\right) \\
L C_{N W 3}=L C_{N W 1}+\left(L C_{N W 2}-L C_{N W 1}\right) \frac{I_{N W}-1,200}{650}
\end{gathered}
$$

Both equation of lane-changing rate are consisting of $L_{S}$ function. This explained weaving length could influence the lane-changing rate. In turn, total lane changing rate 
could be determine by using Eq. (14) to find out the intensity of lane-changing activity at each site.

$$
L C_{A L L}=L C_{W}+L C_{N W}
$$

\section{Findings}

Measurement of short length $L_{S}$ at both sites found that there is no barrier presence to prohibit the vehicles to weave at on-ramp. Therefore, $L_{S}$ was assumed as equal to $L_{B}$. Measurement shows that weaving segment at Site A is longer than Site B. Table 2 shows the result of $L_{S}$ at both sites. The following Figure 1 and Figure 2 show the current geometric and situations along the Federal Road FT050-Jalan Kluang.

Table 2.

\begin{tabular}{|l|l|}
\hline & Short Length, $L_{S}(\mathrm{~m})$ \\
\hline Site A & 358 \\
\hline Site B & 316 \\
\hline
\end{tabular}

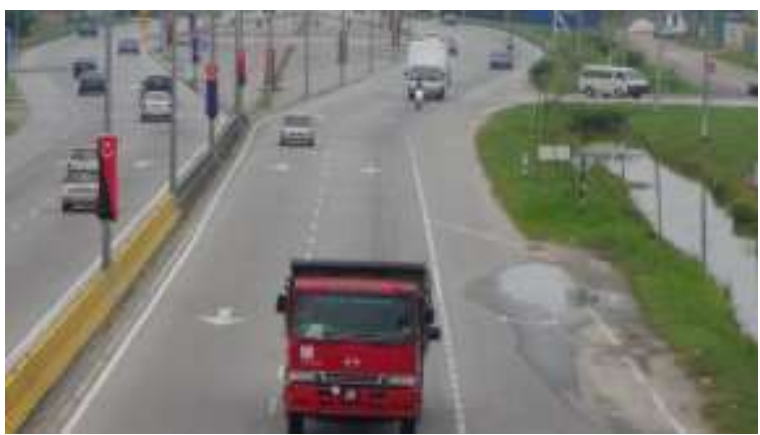

Figure 1 Site A; Federal Road FT050 KM15

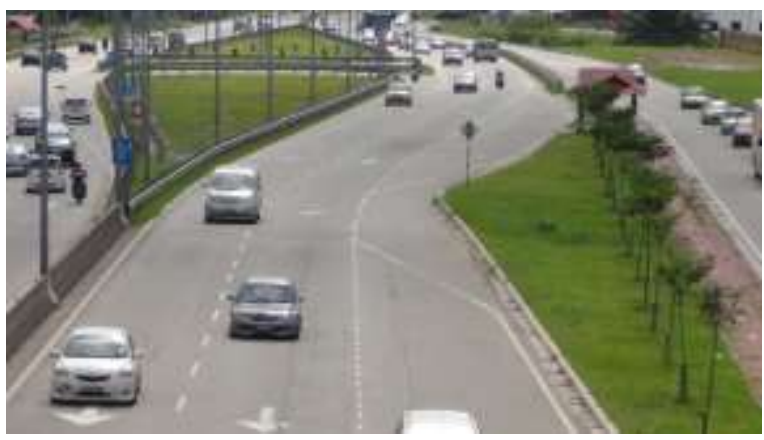

Figure 2 Site B; Federal Road FT050 KM16

Besides, investigation of maximum weaving length was made by using Chapter 12 in HCM 2010 since the value of $L_{M A X}$ for both sections was greater than $L_{S}$. Hence, both sites could be analyzed as weaving section. The analysis found that Site A has more tendencies to encounter weaving turbulence since the value of maximum weaving length is ranging from $(1952 \mathrm{~m}-2120 \mathrm{~m})$ while Site B is ranging from $(1866 \mathrm{~m}-1882 \mathrm{~m})$. This means that the impact of weaving turbulence at Site A could be felt as far as $168 \mathrm{~m}$ meanwhile impact of weaving turbulence at Site B could be felt as far as only $16 \mathrm{~m}$. In term of operational, Site A is worse than Site B. Table 3 and Figure 3 summarize this finding for both sites. 
Table 3. maximum weaving length

\begin{tabular}{|l|l|l|l|l|}
\hline Location & Time Periods & $\begin{array}{l}\text { LMAX } \\
(\mathrm{m})\end{array}$ & $\begin{array}{l}\text { Range } \\
(\mathrm{m})\end{array}$ & $\begin{array}{l}\text { Impact of Weaving } \\
\text { Turbulence } \\
\text { Encountered(m) }\end{array}$ \\
\hline \multirow{3}{*}{ Site A } & $10.00-11.00 \mathrm{am}$ & 2018 & $(1952-2120)$ & 168 \\
& $11.00-12.00 \mathrm{am}$ & 1952 & & \\
\hline & $4.00-5.00 \mathrm{pm}$ & 2082 & & \\
\hline Site B & $5.00-6.00 \mathrm{pm}$ & 2120 & & 16 \\
\hline & $10.00-11.00 \mathrm{am}$ & 1866 & $(1866-$ & \\
& & & $1882)$ & \\
& $11.00-12.00 \mathrm{am}$ & 1867 & & \\
& $4.00-5.00 \mathrm{pm}$ & 1882 & & \\
& $5.00-6.00 \mathrm{pm}$ & 1875 & & \\
\hline
\end{tabular}

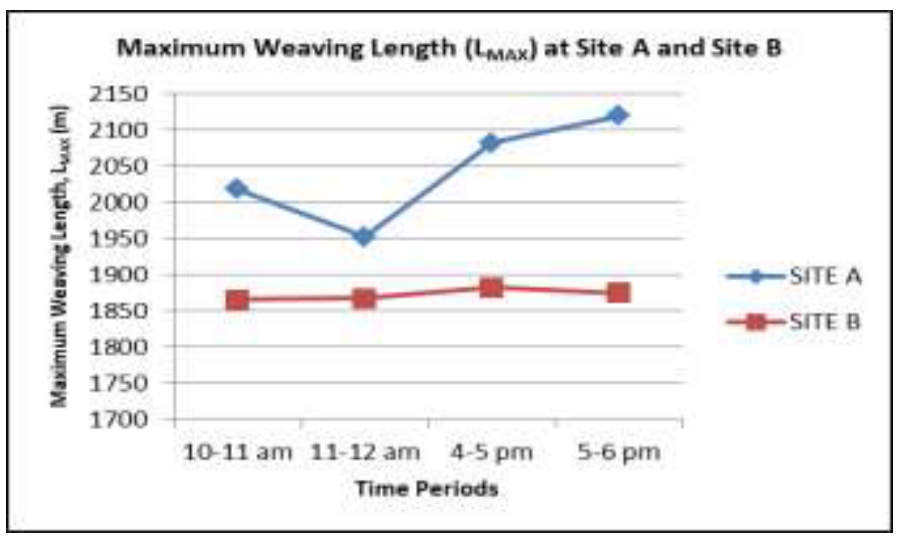

Figure 3. Graph of maximum weaving length at sites

In turn, analysis of lane-changing rate found that the most intense lane-changing activity of weaving occurred at Site A with a highest rate $555 \mathrm{lc} / \mathrm{h}$. Meanwhile, a weaving lane-changing with a rate of $254 \mathrm{lc} / \mathrm{h}$ was recorded at Site B. These values were adapted during peak hours in order to obtain the absolute value due to highest volume of vehicles but even during off peak hour's period, Site A still encounter a higher value of $L C_{W}$ compared to Site B. This difference explained that weaving maneuvers frequently happened at Site A with a longer weaving length because drivers more prefer to perform weaving in an unforced circumstance. Shorter length of weaving provides less comfortability to drivers to perform weaving because it happens in crammed situation. Table 4 and Figure 4 illustrate the finding of lane-changing rate of weaving vehicles at both sites.

Table 4. Finding of lane-changing rate of weaving vehicles

\begin{tabular}{|l|l|l|l|}
\hline Location & Time Periods & $\mathrm{LC}_{\mathrm{W}}(\mathrm{lc} / \mathrm{h})$ & $\begin{array}{l}\text { Absolute } \\
(\mathrm{lc} / \mathrm{h})\end{array}$ \\
\hline \multirow{4}{*}{ Site A } & $10.00-11.00 \mathrm{am}$ & 391 & \multirow{2}{*}{555} \\
\cline { 2 - 3 } & $11.00-12.00 \mathrm{am}$ & 319 & \\
\cline { 2 - 3 } & $4.00-5.00 \mathrm{pm}$ & 451 & \\
\cline { 2 - 3 } & $5.00-6.00 \mathrm{pm}$ & 555 & \\
\hline \multirow{3}{*}{ Site B } & $10.00-11.00 \mathrm{am}$ & 190 & \multirow{2}{*}{254} \\
\cline { 2 - 3 } & $4.00-5.00 \mathrm{pm}$ & 254 & \\
\cline { 2 - 3 } & $5.00-6.00 \mathrm{pm}$ & 234 & \\
\hline
\end{tabular}




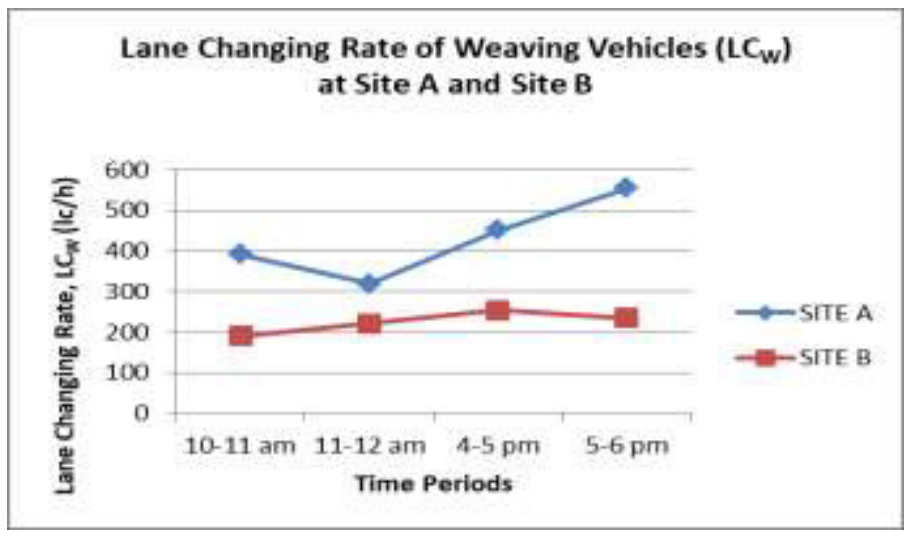

Figure 4. Graph of lane-changing rate of weaving vehicles at sites.

The final finding of this study found that the total lane-changing of both weaving and non-weaving vehicles were absolutely occurred during peak hours and the highest rate recorded at Site A with $1142 \mathrm{lc} / \mathrm{h}$ while Site B is $812 \mathrm{lc} / \mathrm{h}$. This number shows in Table 5 and Figure 5. It also explained that Site A has more tendencies to encounter weaving turbulence due to high lane-changing activity. The high total lane-changing activity somehow affected by a lot of weaving vehicles crossing over the direct traffic. In term of operational, Site B is better than Site A because smooth traffic movement occurred at here. Meanwhile in term of safety, Site B is worse than Site A due to high risk of collision because of shorter weaving length.

Table 5. Finding of total lane-changing rate

\begin{tabular}{|c|c|c|c|}
\hline Location & Time Periods & $\mathrm{LC}_{\mathrm{ALL}}(\mathrm{lc} / \mathrm{h})$ & Absolute LC $\mathrm{LCLL}_{\mathrm{AL}}(\mathrm{lc} / \mathrm{h})$ \\
\hline \multirow{4}{*}{ Site A } & $10.00-11.00 \mathrm{am}$ & 955 & \multirow[t]{4}{*}{1142} \\
\hline & $11.00-12.00 \mathrm{am}$ & 895 & \\
\hline & $4.00-5.00 \mathrm{pm}$ & 999 & \\
\hline & $5.00-6.00 \mathrm{pm}$ & 1142 & \\
\hline \multirow{4}{*}{ Site B } & $10.00-11.00 \mathrm{am}$ & 652 & \multirow[t]{4}{*}{812} \\
\hline & $11.00-12.00 \mathrm{am}$ & 754 & \\
\hline & $4.00-5.00 \mathrm{pm}$ & 812 & \\
\hline & $5.00-6.00 \mathrm{pm}$ & 773 & \\
\hline
\end{tabular}

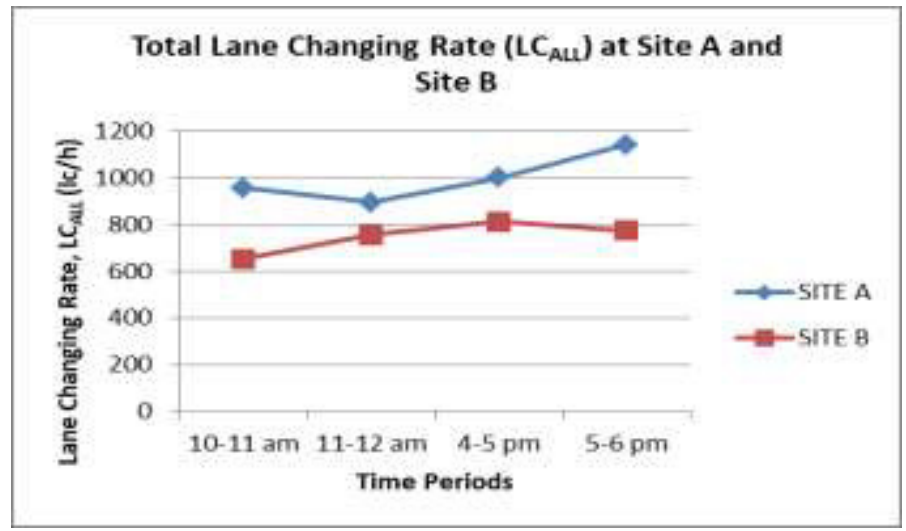

Figure 5. Graph of total lane-changing rate at site A and site B 


\section{Conclusions}

Based on the finding, weaving turbulence tend to occur at Site A because of high number of vehicle using the weaving section at this site. In addition, it is also because of the development nearer to the site especially Taman Universiti residential. The drivers that tend to use the weaving section at this site are mostly consisting of the resident of Taman Universiti residential and also consist of students of UTHM. This factor not only leads to high impact of weaving turbulence but also increasing in lane-changing rate especially for weaving vehicles. Development available around the site is a factor that encourages the high intensity of weaving's lane-changing activity other than weaving length factor.

\section{Acknowledgements}

The authors would like to thank to the Universiti Tun Hussein Onn Malaysia for supporting the study through Contract research grant Vot. U395 and all individuals/organization that have made this study possible. Thank you is also extended to the Department of Transportation Engineering Technology, Faculty of Engineering Technology, Universiti Tun Hussein Onn Malaysia.

\section{References}

1. Cassidy, M. J., \& May, A. D., Proposed Analytical Technique For Estimating Capacity And Level Of Service of Major Freeway Weaving Sections. Transportation Research Record 1320, pp. 99-109. (1991)

2. Prasetijo J., Pour M. H. \& Ghadiri S. M. R., Capacity of Unsignalized Intersections under Mixed Traffic Conditions. Procedia - Social and Behavioral Sciences, Vol.16, pp. 676-685. (2011)

3. Prasetijo J. \& Musa, W. Z., Modeling Zero - Inflated Regression of Road Accidents at Johor Federal Road F001. MATEC Web of Conferences, Vol. 47. (2016)

4. Hosseinpour, M., Yahaya, A. S., Ghadiri, S. M., Prasetijo, J., Application of Adaptive Neuro-fuzzy Inference System for Road Accident. KSCE Journal of Civil Engineering. Vol.17(7), pp. 1761-1772 (2013).

5. Prasetijo J., Capacity and Traffic Performance of Unsignalized Intersections under Mixed Traffic Condition. Ph.D Thesis, Ruhr University Bochum, Germany (2007)

6. Uno N., Iida Y., Itsubo S. \& Yasuhara S., A Microscopic Analysis of Traffic Conflict Caused by Lane-Changing Vehicle at Weaving Section, Kyoto University, Japan. (2002)

7. Halim, H., Adisasmita, S.A., Ramli, M.I., Aly, S.H., The pattern of severity of traffic accidents on traffic conditions heterogeneous. International Journal of Civil Engineering and Technology, Vol. 8(4), pp. 1720-1729. (2017)

8. Crillo, \& Anna, J., The Relationship of Accidents To Length of Speed-Change Laned And Weaving Areas On Interstate Highways. Highway Research Record, pp.17-32. (2002)

9. Shoraka M. \& Che Puan O., Review of Evaluating Existing Capacity of Weaving Segments, Vol. 1(3). (2010)

10. Highway Capacity Manual., Transportation Research Board, National Research Council, Washington, D.C. (2010) 